\title{
Glucocorticoid Suppressible Hyperaldosteronism
}

National Cancer Institute

\section{Source}

National Cancer Institute. Glucocorticoid Suppressible Hyperaldosteronism. NCI

Thesaurus. Code C123248.

Excessive production of aldosterone and elevation of blood pressure by the adrenal gland, which is regulated by corticotropin. 